This Guidance was developed by the Clinical Effectiveness Unit (CEU) of the Faculty of Family Planning and Reproductive Health Care (FFPRHC): Dr Gillian Penney (Director), Dr Susan Brechin (Co-ordinator); Ms Alison de Souza and Ms Gillian Stephen (Research Assistants) in consultation with the Clinical Effectiveness Committee, which includes service user representation and a multidisciplinary Expert Group of health care professionals involved in family planning and reproductive health care. The multidisciplinary group comprised: Dr Alison Fletcher (General Practitioner, St Mary's Medical Centre, Oldham), Dr Gillian Flett (Consultant in Family Planning and Reproductive Health, Aberdeen), Dr Ailsa Gebbie (Consultant in Community Gynaecology, Dean Terrace, Edinburgh), Dr Valerie Godfree (Director of Family Planning and Reproductive Health, Western Sussex PCT), Ms Nancy Graham (Menopause Nurse Specialist, The Sandyford Initiative, Glasgow and Sexual and Reproductive Health Course Organiser, School of Nursing, Midwifery and Community Health, Glasgow Caledonia University, Glasgow), Dr Kate Guthrie (Consultant Community Gynaecologist, Hull and East Yorkshire and FFPRHC Council representative), Dr Ali Kubba (Consultant Community Gynaecologist and Senior Lecturer, Lambeth PCT and Guys' and Kings' Medical School, London), Dr Diana Mansour (Consultant in Community Gynaecology and Reproductive Health Care, Newcastle-upon-Tyne), Dr Louise Massey (Specialist Registrar in Public Health/Trainee Member of the CEU/FFPRHC Education Committee Member), Dr Nicola Mullin (Consultant in Family Planning and Reproductive Health, Halton Primary Care Trust). Written feedback was provided by: Ms Toni Belfield (Director of Information, fpa, London), Dr Joanne Cartwright (FFPRHC Education Committee Member).

This Guidance is also available online at www.ffprhc.uk. Evidence tables are available on the FFPRHC website. These summarise relevant published evidence on contraception for women aged over 40 years, which was identified and appraised in the development of this Guidance. The clinical recommendations within this Guidance (i.e. the text appearing within the blue and red boxes) are based on evidence whenever possible.

\begin{tabular}{|ll|}
\hline \multicolumn{3}{|c|}{ Grades of Recommendations } \\
\hline A & Evidence based on randomised controlled trials (RCTs) \\
\hline B & Evidence based on other robust experimental or observational studies \\
\hline C & Evidence is limited but the advice relies on expert opinion and has the endorsement of respected authorities \\
\hline & Good Practice Point where no evidence exists but where best practice is based on the clinical \\
\hline
\end{tabular}

Electronic searches were performed in general between 1990 and 2004 for: MEDLINE (CD Ovid version); EMBASE (1990-2004); PubMed; The Cochrane Library (to September 2004) and the US National Guideline Clearing House. The searches were performed using relevant medical subject headings $(\mathrm{MeSH})$, terms and text words. The Cochrane Library was searched for systematic reviews, meta-analyses and controlled trials relevant to contraception for women aged over 40 years. Previously existing Guidelines from the FFPRHC, the Royal College of Obstetricians and Gynaecologists (RCOG), the World Health Organization (WHO) and reference lists of identified publications were also searched. Similar search strategies have been used in the development of other national guidelines. Selected key publications were appraised according to standard methodological checklists before conclusions were considered as evidence. Evidence was graded as above, using a scheme similar to that adopted by the RCOG and other guideline development organisations.

\title{
Questions for Contraception for Women Aged Over 40 Years
}

The following questions and answers have been developed by the FFPRHC Education Committee.

Indicate your answer by ticking the appropriate box for each question

1 The perimenopause refers to the phase spanning the transition from normal ovulatory cycles to the cessation of ovulation and menstruation.

2 Women aged over 40 years have a low conception rate, but are much more likely to undergo induced abortion when faced with an unplanned pregnancy than women in their $20 \mathrm{~s}$.

3 In healthy, non-smoking, women aged 40-44 years, the risks of mortality from cardiovascular disease attributable to the combined pill outweigh potential benefits.

4 WHOMEC recommends that the risks of combined contraception in women over the age of 35 years who have migraine with or without aura outweigh any benefits.

5 The risk of endometrial and ovarian carcinomas increases over the age of 40 years. Women in this age group should be informed of at least a $50 \%$ reduction in the risk of these cancers with use of combined oral contraception.

6 A woman who develops a venous thrombosis or has a myocardial infarction or a cerebrovascular accident whilst taking the progestogen-only pill (POP), may be advised that continuing to use this method of contraception represents an acceptable risk.

7 There is evidence that tubal occlusion may precipitate menorrhagia.

8 Some $95.9 \%$ of women will have undergone the menopause by the age of 55 years.

9 A woman having the levonorgestrel-releasing intrauterine system inserted at age $\geq 45$ years can be advised that the device can be retained for up to 7 years, providing it is not being used in combination with oestrogen hormone replacement therapy (HRT).

10 A POP does not provide effective contraception when used at the same time as HRT.

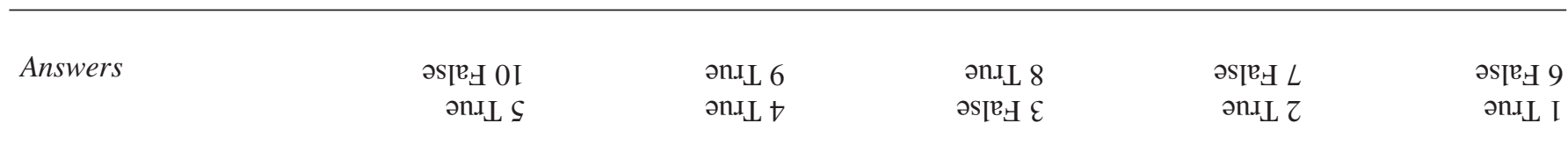

J Fam Plann Reprod Health Care 2005: 31(1) 


\section{Discussion Points for Contraception for Women Aged Over 40 Years}

The following discussion points have been developed by the FFPRHC Education Committee.

\section{Discussion Points}

1 A 42-year-old woman with a recent history of a thrombotic stroke requires long-term effective contraception. Describe her contraceptive options.

2 A 46-year-old local licensee, a smoker of $\geq 15$ cigarettes per day, with a family history of osteoporosis, has been a contented user of Depo-Provera ${ }^{\circledR}$ for 15 years. She is reluctant to make any changes to either her lifestyle or her contraception method. What are the important issues to discuss?

3 A 46-year-old woman presents to you with a positive pregnancy test. She is distraught. She had not thought that she needed to use contraception since she had not had any periods for 6 months. Outline your discussions with her regarding her options. What are the recommendations for stopping contraception at the menopause?

\section{The Janssen-Cilag Travelling Scholarship}

This scholarship, established in memory of Dr Ann Horler, continues to be sponsored by Janssen-Cilag. The purpose of the scholarship is to enable the successful candidate to travel to any country, subject to approval by the selection committee, in order to gain experience that will be applicable to his or her daily work. Those eligible to apply are Diplomates and Members of the Faculty of Family Planning and Reproductive Health Care of the Royal College of Obstetricians and Gynaecologists, who are based in the British Isles and currently working in family planning.

Once the successful scholar is announced at the AGM usually held in May, Janssen-Cilag will arrange presentation of the sponsorship, the value of which is $\mathbf{\$ 2 5 0 0}$, enabling the scholar to make his or her own travelling arrangements. It is expected that the successful candidate will travel before March of the following year and give a report to the annual symposium of the Faculty in that year. This report may be published at a later date in the Journal of Family Planning and Reproductive Health Care. Those wishing to apply for the scholarship are asked to submit a typewritten summary of the proposed project, to include:

- Details of the places, organisations and individuals to be visited, with dates;

- Aims, objectives, benefits and how the experience will assist them in their daily work on their return; and

- A brief curriculum vitae with details of their current post.

Applications should be signed and dated and returned to the Secretary, Faculty of Family Planning and Reproductive Health Care, RCOG, 27 Sussex Place, Regent's Park, London NW1 4RG, UK by 7 April annually.

\section{The 4-0-8 Sheffield Fund}

In 2001 the 4-0-8 Young People's Consultation Centre Ltd, Sheffield, UK made a significant donation to the Faculty of Family Planning and Reproductive Health Care (FFPRHC) for the purpose of funding training for health care professionals who had limited funding for attending training meetings. Any person working in the field of reproductive and sexual health care within the UK may apply. Approximately $£ 1000$ will be allocated every 3 months, either as a single award or divided between the successful applicants.

For details on how to apply to the 4-0-8 Sheffield Fund visit the Faculty website at www.ffprhc.org.uk. For an application form apply to: Chair of the Education Committee, Faculty of Family Planning and Reproductive Health Care of the RCOG, 27 Sussex Place, Regent's Park, London NW1 4RG, UK. Closing date: 6 months prior to the event for which funding is applied for.

\section{The David Bromham Annual Memorial Award}

Details of this award, and a downloadable application form, are available on the Faculty website at www.ffprhc.org.uk (see under sponsorship/awards). Completed submissions for this award must be received at the Faculty office by 10 April annually. 